\title{
MODEL PEMBANGKIT LISTRIK TENAGA PANAS BUMI SISTEM HYBRID FLASH-BINARY DENGAN MEMANFAATKAN PANAS TERBUANG DARI BRINE HASIL FLASHING
}

\author{
Muhamad Ridwan Hamdani ${ }^{\text {a) }}$, Cukup Mulyana ${ }^{\text {b) }}$, Renie Adinda Pitalokha ${ }^{\text {c)}}$, \\ Fajar Muhammad $^{\text {d) }}$
}

Prodi Fisika FMIPA Universitas Padjadjaran, Jl. Raya Bandung-Sumedang Km. 21, Jatinangor 45363

Email: a)hamdanimuhamad12@gmail.com, b)c.mulyana55@yahoo.com, c)renie.adinda@gmail.com, d)fajaarmuhammad@yahoo.com

\begin{abstract}
Abstrak
Potensi panas bumi di Indonesia sangat melimpah, yaitu terdapat 256 prospek dengan potensi sekitar 28.617 MW. Sumber panas bumi di Indonesia merupakan sumber dengan sistem hydrothermal yang didominasi oleh jenis dominasi air, dengan karakteristik sekitar 20\% uap dan $80 \%$ air. Jenis pembangkit di Indonesia yang digunakan untuk memanfaatkan sumber dominasi air ini adalah sistem single-flash. Brine hasil flashing dari sistem ini masih memiliki temperatur yang tinggi sehingga masih bisa digunakan sebagai sumber energi baru, yaitu dengan diflash ulang maupun digunakan sebagai sumber pemanas pada sistem binary cycle. Oleh karena itu, dibuatlah model pembangkit listrik tenaga panas bumi sistem hybrid flash-binary untuk memanfaatkan brine hasil flashing sehingga diperoleh daya yang lebih besar. Pada penelitian ini digunakan software HYSYS 7.0 dalam pembuatan modelnya dan dibuktikan dengan perhitungan termodinamik pada setiap bagiannya. Pada penelitian ini telah dibuat model pembangkit listrik tenaga panas bumi yang menghasilkan total daya 279,178 MW dan penambahan daya $32,91 \%$ tanpa harus membuat sumur produksi baru.
\end{abstract}

Kata-kata kunci: flashing, binary cycle, HYSYS 7.0, hybrid flash-binary

\begin{abstract}
Indonesia has a great number of geothermal sources, there are 256 prospects with $28,617 \mathrm{MW}$ potential power. The sources is dominated by hydrothermal system that usually has $20 \%$ vapor and $80 \%$ liquid. The power plant that appropriate to used is single-flash system. In this system, the brine which has a great number of enthalpy is reinjected to reservoir. This research was performed to design the hybrid flash-binary system power plant model by utilizing the wasted brine to gain the greater power. HYSYS 7.0 was used to made the model and based on the fundamental thermodynamic principles energy and mass conservation calculation in every single part of the plant. The hybrid flash-binary system model was made and resulted additional power $32.91 \%$ with $279.178 \mathrm{MW}$ total power without drilling the new production well.
\end{abstract}

Keywords: flashing, binary cycle, hybrid flash-binary, HYSYS 7.0

\section{PENDAHULUAN}

Potensi panas bumi di Indonesia sangat melimpah, yaitu terdapat 256 prospek dengan potensi daya sekitar 28.617MW. Sistem panas bumi di Indonesia pada umumnya merupakan sistem hydrothermal bertemperatur tinggi, $>255^{\circ} \mathrm{C}$, dan hanya beberapa diantaranya yang bertemperatur sedang, $150^{\circ} \mathrm{C}-225^{\circ} \mathrm{C}[1]$. Karakteristik tersebut sangat berpotensi untuk dimanfaatkan menjadi energi 
listrik. Sistem hydrothermal yang ada di Indonesia didominasi oleh jenis dominasi air, dengan karakteristik fluida panas bumi sekitar 20\% uap dan $80 \%$ air. Jenis pembangkit listrik yang cocok digunakan untuk memanfaatkan potensi energi ini adalah pembangkit listrik tenaga panas bumi sistem flashing (single-flash ataupun multi-flash).

Pembangkit listrik tenaga panas bumi di Indonesia yang digunakan unutk memanfaatkan sumber hydrothermal dominasi air adalah sistem single-flash. Pada sistem ini, fluida berfase cair (brine) hasil flashing langsung diinjeksikan kembali ke perut bumi (reservoir). Brine tersebut masih memiliki temperatur dan tekanan yang cukup tinggi untuk membangkitkan energi listrik. Untuk memanfaatkan potensi energi tersebut dapat digunakan jenis pembangkit listrik sistem multi-flash, binary cycle, atau dengan menggabungkan kedua sistem tersebut (hybrid flash-binary).

Tujuan dari penelitian ini adalah membuat model pembangkit listrik tenaga panas bumi sistem hybrid flash-binary dengan memanfaatkan panas terbuang dari brine hasil flashing agar dapat diperoleh daya yang lebih besar tanpa harus membuat sumur produksi yang baru. Model pembangkit listrik sistem ini dibuat menggunakan software HYSYS 7.0 dan dilakukan perhitungan termodinamika pada setiap bagian pembangkitnya.

\section{A. Pembangkit Listrik Sistem Single-flash}

Gambar 1. menunjukkan diagram alir dan diagram Temperatur-entropi(T-s) dari pembangkit listrik sistem single-flash. Fluida panas bumi pada titik 1 berasal dari reservoir, memiliki tekanan dan temperatur tinggi, dialirkan menuju titik 2 melewati sumur produksi dan mengalami proses flashing yang menyebabkan sebagian fluida panas bumi tersebut berubah fase menjadi fase uap. Separator digunakan untuk memisahkan fase uap dan fase cair dari fluida tersebut. Fluida cair (brine) hasil flashing akan mengalir melalui titik 3, sedangkan fluida uap (steam) akan dialirkan melalui titik 5 menuju turbin untuk memutar turbin yang kemudian menghasilkan daya listrik. Steam yang keluar dari turbin (titik 6) mengalami penurunan tekanan dan dialirkan menuju kondenser untuk dikondensasi menjadi fase cair (titik 7). Brine dari titik 7 dan titik 3 diinjeksikan kembali ke sumur injeksi menggunakan pompa injeksi.

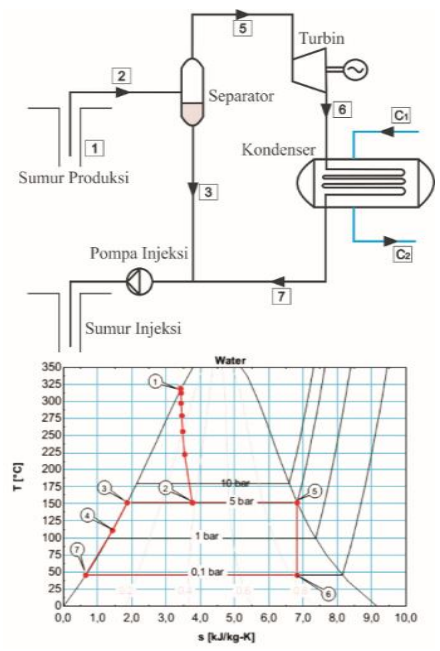

Gambar 1. Diagram alir (atas) dan diagram T-s (bawah) pembangkit listrik tenaga panas bumi sistem single-flash[2].

\section{B. Pembangkit Listrik Sistem Double-Flash}

Pembangkit jenis double-flash merupakan pengembangan atau modifikasi dari sistem single-flash untuk sumber panas bumi dominasi air. Brine hasil flashing pada sistem single-flash (titik 3), yang biasanya diinjeksikan kembali menuju sumur injeksi, diflash ulang menggunakan throttle valve untuk mendapatkan uap lebih banyak (titik 8) dan dialirkan menuju turbin untuk dapat menghasilkan daya listrik yang lebih besar. Gambar 2. menunjukkan diagram T-s dan diagram alir pembangkit listrik sistem double-flash. 


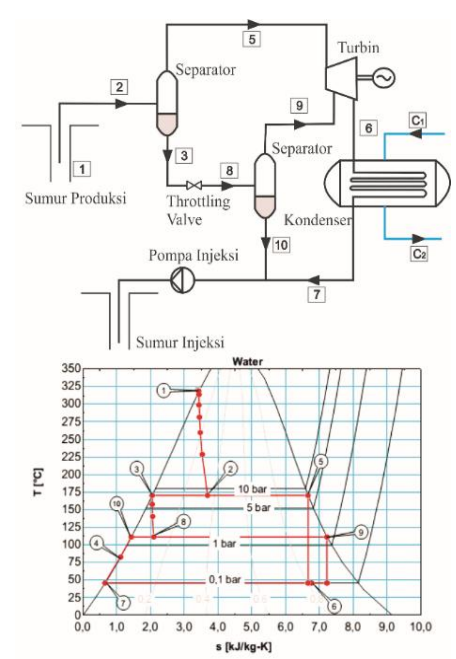

Gambar 2. Diagram alir (atas) dan diagram T-s (bawah) pembangkit listrik tenaga panas bumi sistem double-flash[2].

Separator yang digunakan setelah proses flashing kedua merupakan low pressure separator karena tekanan hasil flashing tersebut jauh lebih kecil dibandingkan flashing pertama. Brine hasil kondensasi (titik 7) dan yang keluar dari separator kedua (titik 10) dialirkan menuju sumur injeksi menggunakan pompa injeksi.

Selama proses flashing kedua, enthalpy fluida sebelum dan setelahnya tetap konstan[3]

$$
h_{3}=h_{8}
$$

dengan $h_{3}$ adalah enthalpy fluida di titik 3 (sebelum flashing) dan $h_{8}$ adalah enthalpy fluida di titik 8 (setelah flashing). Kualitas uap yang dihasilkan dari proses flashing kedua dapat diketahui dengan menggunakan persamaan (2)

$$
x=\frac{h_{8}-h_{10}}{h_{9}-h_{10}}
$$
10

dengan $x$ adalah kualitas uap hasil flashing, $h_{9}$ dan $h_{10}$ adalah enthalpy fluida di titik 9 dan di titik

\section{Pembangkit Listrik Sistem Binary-Cycle}

Konsep dasar pembangkit listrik sistem binary cycle, dikenal dengan siklus rankin organik (SRO), merupakan modifikasi dari siklus rankin dimana fluida kerjanya menggunakan fluida organik yang memiliki temperatur didih dan tekanan uap yang lebih tinggi dibandingkan air[4]. Binary cycle pada panas bumi terdiri atas dua siklus, yaitu siklus primer yang terdiri dari fluida panas bumi, dan siklus sekunder dimana fluida kerja organik bersirkulasi.

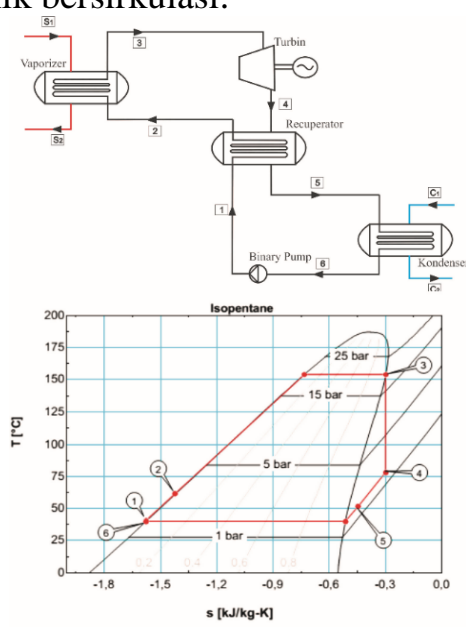

Gambar 3. Diagram alir (atas) dan diagram T-s (bawah) pembangkit listrik tenaga panas bumi sistem binar cycle menggunakan recuperator[2].

Pengembangan dari jenis binary cycle adalah dengan menggunakan recuperator yang merupakan tipe lain dari heat exchanger. Fungsi dari alat ini adalah untuk meningkatkan temperatur fluida kerja 
ketika akan memasuki vaporizer. Selain itu, brine yang keluar dari vaporizer akan memiliki temperatur yang lebih tinggi dibandingkan tanpa adanya recuperator[5].

Gambar 3. menunjukkan diagram alir dan diagram T-s dari pembangkit listrik sistem binary cycle menggunakan recuperator. Brine dari sumur produksi (s1) dialirkan menuju vaporizer dan digunakan sebagai pemanas untuk menguapkan fluida kerja organik dan keluar menuju sumur injeksi (s2). Pada saat yang bersamaan, fluida kerja organik (titik 2) memasuki vaporizer dan fasenya berubah akibat terjadinya pertukaran panas antara fluida kerja dan brine. Proses pertukaran panas tersebut dapat ditinjau secara termodinamik menggunakan persamaan (3)

$$
\dot{m}_{b}\left(h_{s 1}-h_{s 2}\right)=\dot{m}_{w f}\left(h_{3}-h_{2}\right)
$$

dengan $\dot{m}_{b}$ merupakan laju alir massa dari brine, $h_{s 1}$ dan $h_{s 2}$ adalah enthalpy brine yang masuk dan keluar vaporizer, $\dot{m}_{w f}$ adalah laju alir massa fluida kerja, $h_{3}$ dan $h_{2}$ adalah enthalpy fluida kerja yang masuk dan keluar vaporizer.

Fluida kerja organik yang berfase uap (titik 3 ) dialirkan melalui turbin sehingga dihasilkan daya turbin. Besarnya daya yang dihasilkan dapat diketahui dengan persamaan (4)

$$
\dot{W}_{t}=\dot{m}_{w f}\left(h_{3}-h_{4}\right)
$$

dengan $\dot{W}_{t}$ adalah daya turbin persatuan massa fluida yang mengalir melalui turbin, dan $h_{4}$ adalah enthalpy fluida kerja yang keluar dari turbin.

Fluida kerja yang keluar dari turbin mengalami penurunan tekanan namun masih memiliki temperatur yang cukup tinggi dan dialirkan ke recuperator yang kemudian dikondensasi di kondenser sehingga berubah fase menjadi fluida cair. Proses perubahan fase yang terjadi di kondenser dapat dihitung dengan persamaan (5)

$$
\dot{m}_{c w}\left(h_{c 2}-h_{c 1}\right)=\dot{m}_{w f}\left(h_{5}-h_{6}\right)
$$

dengan $\dot{m}_{c w}$ adalah laju alir massa air pendingin, $h_{c 2}$ dan $h_{c 1}$ merupakan enthalpy air pendingin yang keluar dan masuk kondenser, $h_{5}$ dan $h_{6}$ adalah enthalpy fluida kerja organik yang masuk dan keluar kondenser. Selanjutnya fluida kerja cair dialirkan menggunakan binary pump (titik 1) menuju recuperator. Fluida pada bagian ini akan bertukar panas dengan bagian fluida yang keluar dari turbin. Pada titik 2 fluida kerja telah mengalami peningkatan temperatur dan tekanan yang selanjutnya dialirkan menuju vaporizer untuk diuapkan kembali. Proses pertukaran panas yang terjadi di recuperator dapat ditinjau menggunakan persamaan (6)

$$
T_{4}-T_{5}=T_{2}-T_{1}
$$

sedangkan efisiensi dari recuperator dapat dihitung menggunakan nilai dari faktor efektivitas $\varepsilon_{r}[6]$,

$$
\varepsilon_{r}=\frac{T_{2}-T_{1}}{T_{4}-T_{1}}
$$

dengan $T_{4}$ adalah temperatur fluida kerja yang keluar dari turbin, $T_{5}$ adalah temperatur fluida kerja yang memasuki kondenser, $T_{2}$ adalah temperatur fluida kerja yang menuju vaporizer, dan $T_{1}$ adalah temperatur fluida kerja yang terkompresi dari pompa.

Jenis fluida organik yang biasa digunakan adalah isopentane $\left(\mathrm{C}_{5} \mathrm{H}_{12}\right)$ yang memiliki nilai $\mathrm{T}_{\mathrm{c}}$ sebesar $193,9^{\circ} \mathrm{C}, \mathrm{P}_{\mathrm{c}}$ sebesar 3,24 MPa, titik didih sebesar $27,7^{\circ} \mathrm{C}$ dan $\mathrm{P}_{\mathrm{s}}$ sebesar 0,07376 $\mathrm{MPa}$ [7].

\section{METODE PENELITIAN}

Metode yang digunakan dalam melakukan penelitian ini adalah studi awal yang terdiri dari studi literatur dan studi lapangan. Studi literatur yang dilakukan adalah kajian mengenai karakteristik fluida panas bumi, prinsip kerja dari sistem pembangkit listrik tenaga panas bumi berdominasi air seperti single-flash, multi-flash, dan binary cycle. Selain itu dikaji pula model pembangkit listrik tenaga panas bumi terintegrasi yang merupakan gabungan dari sistem flashing dan binary cycle. Setelah melakukan studi literatur, dilakukan studi lapangan untuk memperoleh informasi mengenai keadaan riil dari pembangkit listrik tenaga panas bumi berdominasi air yang telah beroperasi di 
Indonesia. Dari hasil studi lapangan diperoleh data temperatur, tekanan, dan mass flow fluida panas bumi yang digunakan untuk mengoperasikan pembangkit tersebut.

Selanjutnya dilakukan perancangan model pembangkit listrik sistem hybrid flash-binary menggunakan software HYSYS 7.0 dengan memasukkan data input pada Tabel 1.

Tabel 1. Karakteristik Fluida Panas Bumi Dominasi Air.

\begin{tabular}{|l|l|l|l|l|}
\hline Cluster & $\begin{array}{l}\mathrm{T} \\
\left({ }^{\circ} \mathrm{C}\right)\end{array}$ & $\begin{array}{l}\mathrm{P} \\
(\text { bar })\end{array}$ & $\begin{array}{l}\dot{m} \\
(\text { ton/jam })\end{array}$ & $\mathrm{X}$ \\
\hline 1 & 180 & 10 & 2300 & 0.2 \\
\hline 2 & 180 & 10 & 2300 & 0.2 \\
\hline 3 & 180 & 10 & 2300 & 0.2 \\
\hline
\end{tabular}

Setelah itu dilakukan pengoptimalan parameter dari model pembangkit yang telah dibuat agar diperoleh daya dan efisiensi yang lebih optimal dan dibuatlah diagram T-s dengan memasukkan parameter dari setiap bagian pembangkit tersebut.

\section{HASIL DAN PEMBAHASAN}

Model pembangkit listrik tenaga panas bumi yang dibuat merupakan pengembangan dari model pembangkit sistem single-flash dengan cara memanfaatkan brine hasil flashing agar dapat diperoleh daya yang lebih besar tanpa harus membuat sumur produksi baru. Model yang telah dibuat merupakan campuran (hybrid) antara pembangkit sistem flashing dengan sistem binary cycle, sehingga disebut sebagai pembangkit listrik sistem hybrid flash-binary seperti ditunjukkan pada Gambar 7. Terdapat total 8 unit pembangkit yang terdiri dari tiga unit single-flash identik (unit 1, 2, dan 3), satu unit double-flash (unit 4), satu unit triple-flash (unit 5), dan tiga unit binary cycle identik yang dilengkapi dengan recuperator (unit 6, 7, dan 8).

Pada model ini digunakan tiga buah cluster sumur yang memproduksi fluida panas bumi dengan karakteristik seperti ditunjukkan pada Tabel 1. Masing-masing cluster digunakan untuk membangkitkan satu unit single-flash identik (unit 1, 2, dan 3). Gambar 4. menunjukkan diagram alir pembangkit unit 1 . Fluida dengan fase uap (titik 2) dialirkan menuju turbin sehingga dihasilkan daya sebesar 69,97MW yang kemudian dikondensasi di kondenser dan diinjeksikan kembali ke sumur injeksi (titik 15-1).

Karakteristik fluida di setiap titik aliran ditunjukkan pada Tabel 2. Oleh karena unit 2 dan unit 3 identik dengan unit 1 maka daya dan karakteristik fluidanya pun identik.

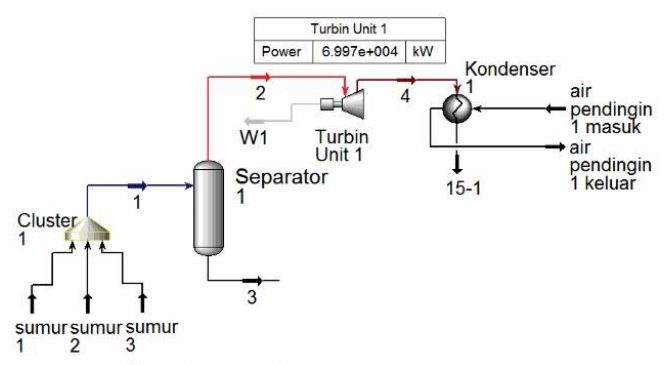

Gambar 4. Diagram alir pembangkit single-flash unit 1.

Pada model ini, diasumsikan efisiensi isentropik turbin adalah $75 \%$ untuk semua turbin yang digunakan di setiap unit.

Tabel 2. Karakteristik fluida di setiap aliran unit 1 .

\begin{tabular}{|l|l|l|l|l|}
\hline Posisi & $\begin{array}{l}\mathrm{T} \\
\left({ }^{\circ} \mathrm{C}\right)\end{array}$ & $\begin{array}{l}\mathrm{P} \\
(\text { bar })\end{array}$ & $\begin{array}{l}\dot{m} \\
\text { (ton/jam) })\end{array}$ & $\mathrm{X}$ \\
\hline $\begin{array}{l}\text { Sumur 1, } \\
\text { 2, dan 3 }\end{array}$ & 266 & 50 & 2300 & 0 \\
\hline 1 & 180 & 10 & 2300 & 0.2 \\
\hline 2 & 180 & 10 & 460 & 1 \\
\hline 3 & 180 & 10 & 1840 & 0 \\
\hline 4 & 41,73 & 0,8 & 460 & 0,87 \\
\hline $15-1$ & 36 & 0,8 & 460 & 0 \\
\hline
\end{tabular}




\begin{tabular}{|l|l|l|l|l|}
\hline $\begin{array}{l}\text { Air } \\
\text { pendingin1 } \\
\text { masuk }\end{array}$ & 25 & 4 & 45510 & 0 \\
\hline $\begin{array}{l}\text { Air } \\
\text { pendingin1 } \\
\text { keluar }\end{array}$ & 30 & 4 & 45510 & 0 \\
\hline
\end{tabular}

Brine hasil flashing pertama (titik 3) dimanfaatkan kembali dengan cara diflash ulang menggunakan throttle valve 1 sehingga diperoleh fase uap sebanyak 3,39\% (titik 5). Proses ini merupakan proes flashing kedua. Brine hasil flashing kedua ini (titik 7) diflash ulang menggunakan throttle valve 4 sehingga diperoleh fase uap sebesar 4,58\% (titik 10).

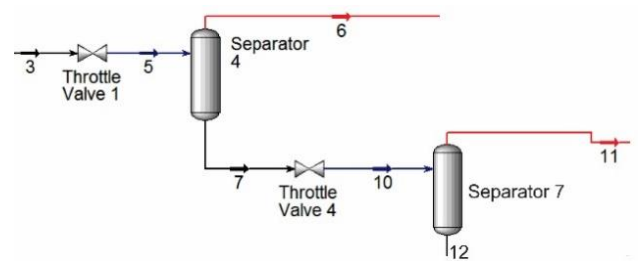

Gambar 5. Proses flashing kedua dan ketiga (brine berasal dari unit 1).

Diagram alir proses flashing kedua dan ketiga ditunjukkan oleh Gambar 5. Fase uap dari hasil flashing kedua (titik 6) digunakan untuk memutarkan turbin di unit 4, dan fase uap hasil flashing ketiga (titik 11) digunakan untuk memutarkan turbin di unit 5.

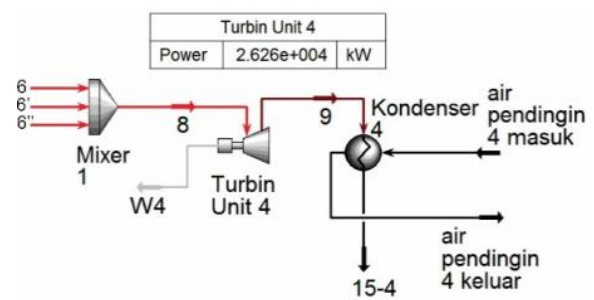

Gambar 6. Diagram alir pembangkit double-flash unit 4.

Gambar 6. menunjukkan diagram alir pembangkit doubel-flash unit 4. Fase uap hasil flashing kedua (titik 6 dari unit 1, titik 6' dari unit 2, dan titik 6" dari unit 3) digabungkan dan digunakan untuk memutarkan turbin di unit 4. Daya yang dihasilkan adalah 26,26MW.

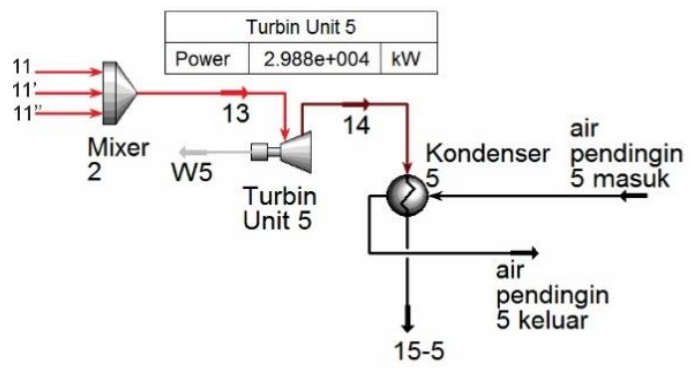

Gambar 7. Diagram alir pembangkit triple-flash unit 5.

Fase uap hasil flashing ketiga (titik 11 dari unit 1, titik 11' dari unit 2, dan titik 11', dari unit 3) digabungkan dan digunakan untuk memutarkan turbin di unit 5. Daya yang dihasilkan adalah 29,88MW. Diagram alir pembangkit unit 5 ditunjukkan oleh Gambar 7.

Brine hasil flashing ketiga (titik 12) masih bisa dimanfaatkan sebagai sumber panas pada pembangkit sistem binary cycle unit 6 . Pada sistem ini digunakan isopentane sebagai fluida kerja oganik. Hasil pengujian menggunakan software HYSYS 7.0 menunjukkan bahwa isopentane merupakan fluida kerja organik yang paling optimal dibandingkan dengan fluida kerja organik lainnya (n-pentane, n-butane, i-butane, R-134). Daya yang dihasilkan oleh pembangkit ini adalah 4,593MW.

Oleh karena fluida hasil flashing ketiga dari unit 2 (titik 12') dan unit 3 (titik 12')) identik maka pembangkit binary cycle unit 7 dan unit 8 menghasilkan daya yang sama dengan unit 6 . Diagram alir 
pembangkit ini ditunjukkan oleh Gambar 8. Karakteristik fluida di setiap titik unit pembangkit ditunjukkan oleh Tabel 3 .

Daya total yang dihasilkan oleh model pembangkit listrik sistem hybrid flash-binary adalah 279,178MW. Bila dibandingkan dengan daya awalnya (unit 1, 2, dan 3 dengan daya masing-masing $69,97 \mathrm{MW}$ ), penambahan daya yang dihasilkan adalah sebesar $32,91 \%$.

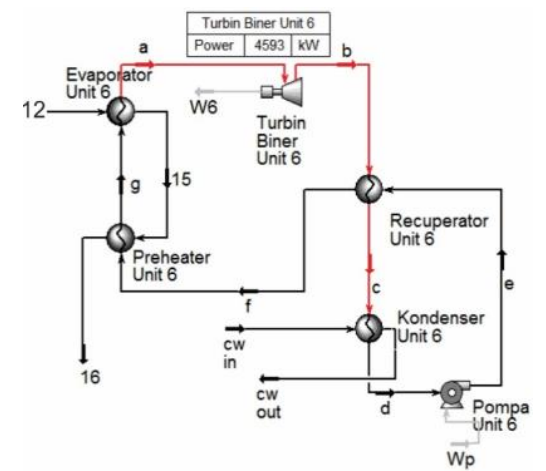

Gambar 8. Diagram alir pembangkit unit 6 yaitu unit binary cycle yang dilengkapi dengan recuperator.

Tabel 3. Karakteristik aliran fluida di setiap titik. (Unit 4 s.d. Unit 8).

\begin{tabular}{|l|l|l|l|l|}
\hline Posisi & $\begin{array}{l}\mathrm{T} \\
\left({ }^{\circ} \mathrm{C}\right)\end{array}$ & $\begin{array}{l}\mathrm{P} \\
(\text { bar })\end{array}$ & $\begin{array}{l}\dot{m} \\
(\text { ton} / \mathrm{h})\end{array}$ & $\mathrm{X}$ \\
\hline 5 & 165 & 7 & 1840 & 0.034 \\
\hline $6,6{ }^{\prime}, 6^{\prime}$ & 165 & 7 & 62,29 & 1 \\
\hline 7 & 165 & 7 & 1778 & 0 \\
\hline 8 & 165 & 7 & 186,9 & 1 \\
\hline 9 & 41,73 & 0,8 & 186,9 & 0,87 \\
\hline 10 & 143,5 & 4 & 1778 & 0,04 \\
\hline $11,11^{\prime}, 11^{\prime}$, & 143,5 & 4 & 81,42 & 1 \\
\hline 13 & 143,5 & 4 & 244,3 & 1 \\
\hline 14 & 41,73 & 0,8 & 244,3 & 0,89 \\
\hline 12 & 143,5 & 4 & 1696 & 0 \\
\hline 15 & 130 & 4 & 1696 & 0 \\
\hline 16 & 125 & 4 & 1696 & 0 \\
\hline a & 125,6 & 12 & 327,7 & 1 \\
\hline b & 86,37 & 2 & 327,7 & 1 \\
\hline c & 53,35 & 2 & 327,7 & 1 \\
\hline d & 27,46 & 1 & 327,7 & 0 \\
\hline e & 28,16 & 12 & 327,7 & 0 \\
\hline f & 55,15 & 12 & 327,7 & 0 \\
\hline g & 100 & 12 & 327,7 & 0 \\
\hline cw in & 25 & 4 & 14570 & 0 \\
\hline cw out & 27 & 4 & 14570 & 0 \\
\hline & & & & \\
\hline
\end{tabular}

\section{KESIMPULAN}

Berdasarkan hasil penelitian telah diperoleh model pembangkit listrik tenaga panas bumi sistem hybrid flash-binary yang menghasilkan daya total $279,178 \mathrm{MW}$ dan penambahan daya $32,91 \%$ tanpa harus membuat sumur produksi baru. 


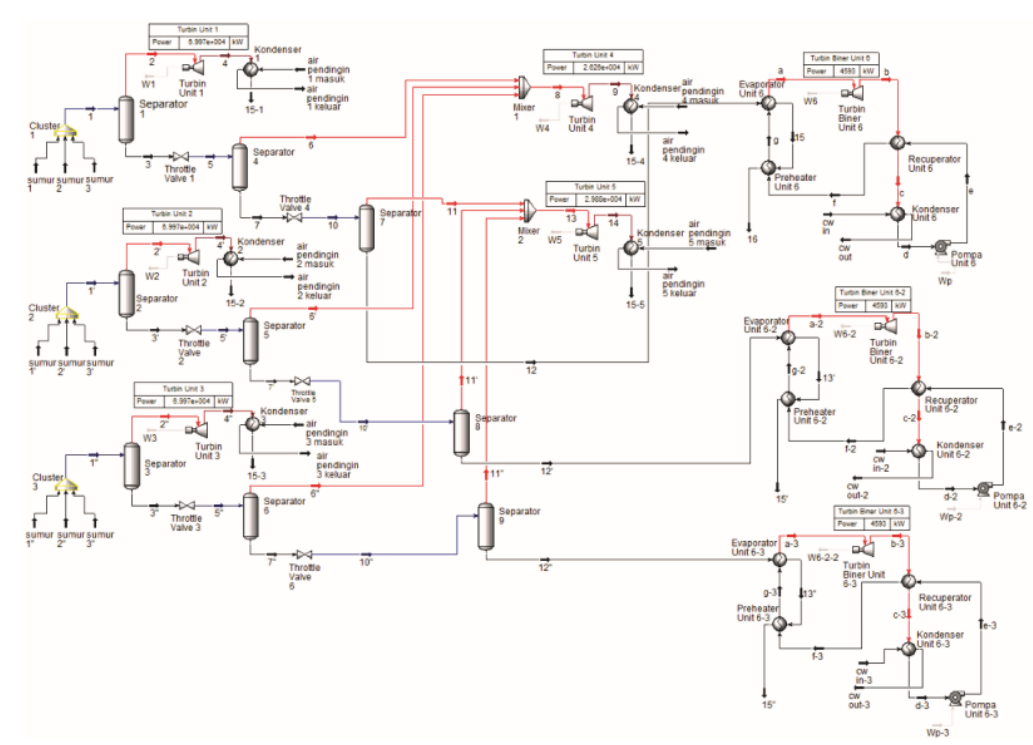

Gambar 9. Diagram alir pembangkit listrik tenaga panas bumi sistem hybrid flash -binary.

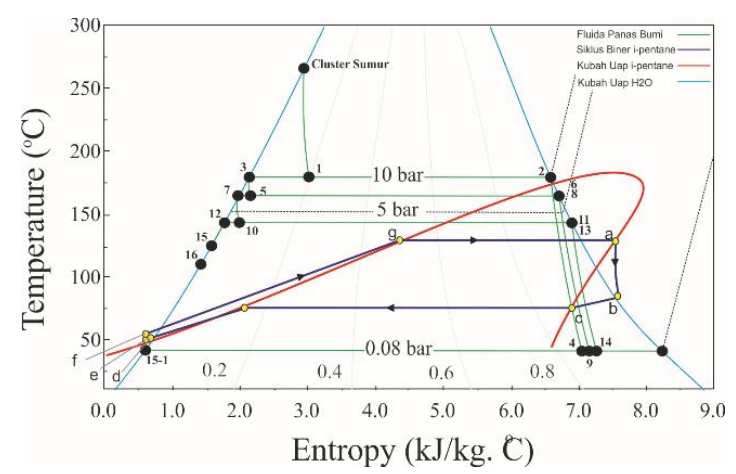

Gambar 10. Diagram T-s pembangkit listrik tenaga panas bumi sistem hybrid flash -binary.

\section{UCAPAN TERIMAKASIH}

Ucapan terima kasih kami sampaikan kepada Prodi Fisika Universitas Padjadjaran yang telah memfasilitasi kami dalam melakukan penelitian ini.

\section{DAFTAR ACUAN}

[1] Saptadji, Nenny, Energi panas bumi (geothermal energy), Bandung. 2009

[2] P. Valdimarsson, Geothermal power plant cycles and main components, UNU-GTP, Icelands (2011), p. 2-6

[3] Dipippo Ronald, Geothermal Power Plants. Principles, Applications, Case Studies and Enviromental Impact. $2^{\text {nd }}$ ed. Massachusetts (2007), p.118

[4] A. F. M. Parada, Geothermal binar cycle power plant principles, operation, and maintenance,UNU-GTPReports Number 20 (2013), p. 446-447.

[5] C. Mulyana, A. H. Saad, M. R. Hamdani, F. Muhammad,The development of integrated plant model by utilizing wasted heat in water-dominated geothermal source, $5^{\text {th }}$ ITB International Geothermal Workshop, Bandung (2016).

[6] O. O. Omatete, P. J. Maziasz, B. A. Pint, and D. P. Stinton, Assessment of recuperator materials for microturbines, Oak Ridge National Laboatory (2000), p. 6.

[7] Dipippo Ronald, Geothermal Power Plants. Principles, Applications, Case Studies and Enviromental Impact. $2^{\text {nd }}$ ed. Massachusetts (2007), p.165 